\title{
Reescrituras en Soldados de Salamina o las sendas de la memoria: desplazamientos de la literatura en el cine y en la narración figurativa
}

\section{Re-writings in Soldiers of Salamis or the paths of memory: displacements of literature in cinema and graphic novel}

\author{
DAVID GARCÍA-REYES \\ Universidad de Concepción (Chile) \\ mangarcia@udec.cl \\ ORCID ID: 0000-0003-3445-1304
}

\begin{abstract}
Resumen: El estudio realiza una búsqueda sobre las intersecciones que se producen en el cine y en el cómic a partir de un texto fuente como Soldados de Salamina (2001) de Javier Cercas. Se abordan las prácticas reescriturales, los intersticios, las permutas y los cambios operacionales más destacados que se efectúan en el film Soldados de Salamina (2003) de David Trueba y en la novela gráfica Soldados de Salamina (2019) de José Pablo García. En los tres textos la memoria tiene un sentido y una representación distintos, pero enfrentan el desarrollo de la trama como una indagación autónoma y se produce un diálogo que enriquece las reflexiones que se derivan del conjunto de cada una de las manifestaciones, estimulando el debate que propician los diferentes puntos de vista.
\end{abstract}

Palabras clave: literatura, cine, cómic, memoria histórica, Javier Cercas, David Trueba, José Pablo García.

\begin{abstract}
The study proposes a search on the gaps of indeterminacy of Soldados de Salamina (2001) by Javier Cercas, produced in film and comics from a source text. The rewriting practices, the interstices, the swaps and the operational changes generated in the film Soldados de Salamina (2003) by David Trueba and in the graphic novel Soldados de Salamina (2019) by José Pablo García provide the basis for the study. In the three texts, memory has a different meaning and representation, but approach the development of the plot as an autonomous inquiry and a dialogue is produced that enriches the notions of the three texts, a dialogue that encourages debate on the points of view.
\end{abstract}

Key Words: literature, cinema, comic, historical memory, Javier Cercas, David Trueba, José Pablo García. 


\section{David García-Reyes}

\section{LA DIMENSIÓN DEL CAMPO DE BATALLA: ESPACIOS DE LA FICCIÓN ${ }^{1}$}

La compresión del ejercicio comparatista suele desarrollarse a partir del uso de herramientas que proporcionan a los análisis atributos funcionales y operativos para generar y articular reflexiones que provean al estudio de la capacidad para aportar desde la semiótica y los análisis intermediales insumos para señalar la significación referencial del objeto de estudio. En esta línea, trabajar la referencialidad permite complementarse con el concepto de los espacios de indeterminación, acuñado por Roman Ingarden y desarrollado posteriormente por Wolfgang Iser (1987). Espacios de indeterminación que toda ficción contiene y que suponen una instancia decisiva para la recepción de las distintas figuras que acceden a un texto - sea este literario, audiovisual, secuencial o de otra índole- desde un posicionamiento como lector, espectador, usuario o -incluso dentro de la iconosfera- un ámbito en el que los parámetros de consumidor han evolucionado en la noción de prosumidor, aquel actante que aporta o retroalimenta desde el territorio transmedia (Scolari, 2019), prosumidor que rompe y expande esos espacios de la ficción, produciendo o señalando posibles contenidos que facilitarán los caminos de esos artífices, sean novelistas, dramaturgos, showrunners televisivos, historietistas o creadores de videojuego. Dentro de esta sucinta pero amplia galería de categorías, la jerarquización en la que a veces se incurre a la hora de ordenar los productos culturales viene precedida por premisas morales, fundamentos basados en el prejuicio y la falta de rigor, que tal y como sugería Robert Stam (2014), resultan tremendamente estériles y son profundamente improductivos desde parámetros científicos.

Dentro del variado corpus que los investigadores asimilan a partir del comparatismo entre el texto literario y el texto audiovisual, nuevos actores se suman a estos procesos de transposición desde un medio o formato y su transformación a otras manifestaciones. De forma privilegiada por su consolidación dentro de las industrias culturales, surge el cómic, cuya feliz aparición en forma de novela gráfica ha permitido consolidar un formato que en realidad era prexistente a su fijación casi canónica como obra de largo aliento. Pero desde esa constitución como género -alumbrada por la importancia de la trilogía $A$ Contract with God (1978-1995) de Will Eisner y Maus (1991) de Art Spiegelman- la novela gráfica viene a redimensionar a nivel global la importancia de la narración figurativa como una forma de expresión de enorme riqueza y complejidad.

Las evidentes diferencias que cada uno de los tres lenguajes -la prosa literaria, la narración audiovisual y el cómic- presentan no deja de ser un

\footnotetext{
${ }^{1}$ Artículo realizado en el marco del Proyecto Desplazamientos, emergencias y nuevos sujetos sociales en el cine español (1996-2011) (DENSSCE96-11), financiado por el MICINN y con el auspicio de una beca de la AUIP (Asociación Universitaria Iberoamericana de Postgrado) para la Movilidad entre Universidades Andaluzas e Iberoamericanas (2019) desarrollada en la Universidad de Sevilla.
} 
desafío para verificar analogías y divergencias, pero fundamentalmente plantea trabajos de análisis en los que poder certificar la distinta naturaleza y los caminos estéticos y éticos que se generan. Aunque pueda parecer una obviedad, compartir el argumento por parte de los tres objetos de estudio no es sinónimo de homogeneidad en el análisis; dicho trabajo evalúa la escritura que de forma autónoma elaboran y reelaboran los creadores, independientemente del medio, además de otras muchas particularidades, entre las que se puede aludir al contexto de producción. En este sentido, el presente estudio examina cómo el film busca una diferenciación sistemática frente a la novela, el lenguaje audiovisual sustancia su peso específico para generar un desplazamiento notable. En cambio, la novela gráfica a veces adolece de una dependencia que la lleva a mostrar cierta rigidez narrativa a la hora de emanciparse del texto fuente o novela matricial y explorar desde el lenguaje del cómic las enormes posibilidades del relato, quizás por la naturaleza del trabajo, un encargo editorial, y el riesgo que suponía adaptar una novela tan significativa. No obstante, resulta innegable la impronta autoral de José Pablo García, que no solo expande el universo de Cercas, sino que se permite dialogar con la película empleando los segmentos de entrevistas a los amigos del bosque, sirviendo de inspiración para la composición de muchas de las secuencias de la novela gráfica, destacando permutas que, del mismo modo que en el largometraje, actuaban en beneficio del relato, textualizando visualmente la trama y enriqueciendo acciones de reescritura. Todo proceso de reescritura es finalmente un acto creativo que implica una relectura, y puede haber tantas como lectores y perspectivas.

La presentación del análisis comparatista entres tres objetos de estudio que vienen precedidos por la publicación y recepción del primero se ordena a partir del diálogo con la novela fuente, Soldados de Salamina (2001) de Javier Cercas (Ibahernando, Cáceres, 1962), una obra que supuso un hito dentro de la renovación literaria en la prosa hispánica y que acompañó los caminos explorados por otros autores en lengua española, cuyo paradigma es Roberto Bolaño. Después de dos décadas de trayecto y recepción como texto literario, la posterior consolidación como autor de Cercas permite rastrear la importancia de su novela en su producción ulterior y resulta llamativo que «una exigua minoría académica» entendiese Soldados de Salamina «como un libro revisionista, equidistante, indulgente con el falangismo o [...] en el colmo del delirio, como una vindicación del mismo» (Ródenas de Moya, 2017: 169); o bien que, como señala Fernando Larraz, coincidiendo «muy oportunamente con el inicio del llamado boom de la memoria histórica [...], la mayor parte de los críticos se hayan detenido a alabar sus rasgos discursivos más que a analizar su expresa interpretación ideológica» (2014: 348). Al margen de lo que algunos pudieran apuntar, guiándose por preferencias formales o estéticas, la novela rebasó las expectativas de Cercas y «trascendió su condición [...] literaria para convertirse en un catalizador de ansiedades y anhelos 


\section{David García-Reyes}

dispersos en la sociedad y en la cultura españolas» (Ródenas de Moya, 2017: 23-24).

En el tiempo transcurrido desde su publicación, la novela ha visto cómo se producían dos reescrituras textuales, articulándose como obras autónomas e independientes, y al mismo tiempo complementarias, aunque esto ya dependa de cada lector o de cada espectador. La primera de estas reescrituras llegó pronto: se trata de la traslación audiovisual ejecutada por David Trueba (Madrid, 1969) con su largometraje Soldados de Salamina, que fue estrenado en marzo de 2003. El film supuso, de la misma manera que la novela, una anticipación a cuestiones que fueron sensibles en los cambios de paradigma que la historiografía hispánica y la propia sociedad española venían planteándose respecto de la consideración de la memoria histórica vinculada a la guerra civil española (1936-1939) y a la dictadura franquista (1939-1975). En relación con lo anterior desde hace dos décadas, local y globalmente, es notoria la importancia de la cultura de la memoria; Julio Aróstegui expresa la necesidad de la misma, pues

no restringe el ámbito de su expansión a ese afán por la recuperación del pasado sino que abarca igualmente a la impregnación de las perspectivas temporales por la fijación del «tiempo vivido» y también por las funciones del olvido. La memoria, pues, entendida como la más potente y vital ligazón de la experiencia al pasado y el mayor resorte para su conservación, cuando no el agente de su «invención», se ha situado prácticamente en el centro de las más reiterativas reivindicaciones culturales actuales, de forma que puede pensarse que, bajo la forma de memoria colectiva especialmente, una de las connotaciones de nuestro presente es una nueva valoración de la función y la importancia de la memoria como definidora de pautas culturales (2004: 9).

La novela y el film alimentaron un debate social que llegó a la palestra mediática con más fuerza a partir de la fundación en el año 2000 de la Asociación para la Recuperación de la Memoria Histórica (ARMH), exponiendo una nueva sensibilidad en cuanto a la dinámica y a la percepción que se tenía respecto a la omisión del reconocimiento de aquellos hombres y mujeres que sufrieron la crudeza y la exclusión del conflicto bélico. Muy especialmente el foco se amplió hacia aquellas personas que pertenecían o estaban vinculadas al bando que perdió la guerra, junto con la consiguiente negación y omisión de su memoria durante la dictadura, y el silencio o la atenuación de su importancia en las primeras décadas del regreso democrático. La conclusión más reductiva es que el esfuerzo y el sacrificio de generaciones que conformaban una colectividad se consagraron a verse silenciados, cuando no deturpados, en aras de un pactismo que favoreciese la llegada de un cambio democrático. Ese alto precio supuso que las heridas abiertas por la guerra, lejos de cicatrizar, se extendieran en el tiempo al no dar cauce a una serie de reivindicaciones molares para restaurar la memoria y el testimonio de los muertos, los exiliados, los perseguidos y todos aquellos sujetos, 
individuales y colectivos, disueltos por la necesidad de un contrato social que armonizase al conjunto de la sociedad española.

En este cambio de paradigma, la literatura y el cine cumplirán un papel capital en los procesos por la recuperación de la memoria histórica en España frente a los cuarenta años de la dictadura franquista, teniendo tanto en la novela de Cercas como en la película de Trueba, una enorme importancia la significación de esta recuperación de los relatos y de las voces de los perdedores de la guerra. La novela gráfica Soldados de Salamina (2019) de José Pablo García (Málaga, 1982) llegó mucho después y aglutinó una visión reflexiva que integraba muchos de los caminos emprendidos por Cercas y Trueba, y a su vez podía distanciarse y aportar otras capilaridades y otros modos de afrontar el relato. En este sentido aparece una novela gráfica que expone este proceso de recuperación de la memoria -y marca el camino que ha seguido el medio desde entonces en el ámbito español-: se trata de El arte de volar (2009) de Antonio Altarriba y Kim, que no solo rinde homenaje a millones de individuos anónimos que se jugaron la vida y el porvenir por sus ideales y diferentes causas de justicia social, pues se trata de obras, igual que la de Cercas o la de Trueba -y con posterioridad la de García- que ofrecen una nueva mirada cultural frente a la significación de esa militancia. Esta novela gráfica se articula y explica a partir de la biografía del padre de Altarriba, cuyos sacrificios personales más que otra cosa se establecían en una actitud vital, una posición que, a pesar de décadas de oprobio y silencio, se perpetuó en la memoria de estos supervivientes y de muchos de sus descendientes. Estos y otros creadores decidieron no olvidar y mantener viva la llama de la memoria personal que finalmente conforma y explica gran parte de la memoria colectiva y lo que se tiende a denominar aquello que define la identidad de los pueblos. La ficción se convierte por tanto en la antesala de lo que culminará legislativamente en la llamada Ley de Memoria Histórica de España (2007), que señalaba la necesidad de recordar, reconocer y reparar a las víctimas de la guerra civil y de la dictadura (Ródenas de Moya, 2017: 15-16). Las obras señaladas incorporan, de una u otra manera, una mirada al pasado y una pesquisa que se constituye en una exploración de lo identitario, en la definición según la cual se produce una identificación con personajes del pasado, testigos o protagonistas de los hechos narrados. En esta senda ficcional el lector y el espectador pueden sacar sus propias conclusiones y conectar con cuestiones que aluden a hechos que se suelen vincular con la memoria personal y familiar de millones de personas. En este sentido, Elina Liikanen apunta que se restablece una conexión entre el pasado y el tiempo presente que afirma señas de identidad y pertenencia a una comunidad específica (2013: 81), estableciéndose el relato ficcional como un instrumento para aprehender e integrar hechos pasados sepultados, ignorados o distorsionados por ciertas corrientes oficiales u oficialistas de la historia o de la comunicación, más interesadas en superar conflictos o polémicas a base de atenuar crímenes o 


\section{David García-Reyes}

injusticias constatadas, del mismo modo que el revisionismo se vale de otras estrategias para defender posiciones fundadas en posicionamientos arbitrarios e interesados, abyectamente perversos.

\section{Cercas y los Caminos del Relato}

En todo este deambular creativo y analítico, en su producción novelística, Javier Cercas emplea el recurso de crear personajes que comparten su nombre y una caracterización que le aproxima al escritor, pero es una construcción ficcional que funciona como estrategia literaria. En el caso Soldados de Salamina, y recurriendo a un ejercicio de síntesis, se puede considerar que el novelista insufla en su libro «vida a un personaje llamado Javier Cercas que se lanza a la calle a construir un "relato real" que consiga contar la historia de una mirada: ese instante fugaz y metafórico en que un soldado anónimo le perdona la vida al escritor falangista Rafael Sánchez Mazas» (Gil Montoya, 2013: 82). A partir de lo que es o puede parecer un pretexto, la forma de contar el relato cobra una importancia superlativa, de la misma manera que también se configuran multitud de reflexiones molares en lo que supone la indagación de una figura como la del escritor Rafael Sánchez Mazas, uno de los líderes, ideólogos y fundadores de la Falange, clave para entender la pátina nacionalista y los atributos que el régimen franquista fagocitó. De su prolífica invención inspirada por el Fascismo italiano -que conoció de primera mano como periodista- surgió el grito «iArriba España!», y contribuyó decisivamente en la composición del «Cara al sol», el célebre himno falangista. El nuevo régimen no dudó en apropiarse de la doctrina y de los símbolos falangistas en aras de reforzar el culto a la personalidad del líder y a constituir la encarnación mítica e idílica de una España imperial y gloriosa recuperada en la persona y los valores encarnados por Francisco Franco, investido y autodenominado como Caudillo de España.

El interés de la investigación se concreta al entrevistar al escritor Rafael Sánchez Ferlosio, hijo de Sánchez Mazas, que visita Girona en unas conferencias en la Universidad en 1994; el protagonista conoce la anécdota del líder falangista salvando la vida tras escapar de un fusilamiento masivo y de un miliciano que le deja marchar. Todo se va precipitando cuando tanto el Cercas autor como el periodista homónimo que es su protagonista publican el artículo «Un secreto esencial» (aparecido originalmente en la edición catalana de El País, 11/03/1999), coincidiendo con el aniversario de la guerra civil. En el texto se entrecruzan los últimos tiempos de Antonio Machado y las peripecias de Sánchez Mazas en la comarca catalana de Collell huyendo de los republicanos, del hambre, del frío y de la muerte; la historia que quiere contar se proyecta como germen de la novela y se insertará en ella; además, de forma sutil anuncia las preguntas que intentará responder y el «nunca sabremos» pasa a ser un intento de respuesta: 
quién fue aquel miliciano que salvó la vida de Sánchez Mazas, ni qué es lo que pasó por su mente cuando le miró a los ojos; nunca sabremos qué se dijeron José y Manuel Machado ante la tumba de su hermano Antonio y de su madre. No sé por qué, pero a veces me digo que, si consiguiéramos desvelar uno de esos dos secretos paralelos, quizá rozaríamos también un secreto mucho más esencial (Cercas, 2017: 208).

Desde el artículo periodístico en la narración se produce esa confrontación especular entre dos relatos cruzados, uno visible y otro invisible, esa idea permanente en la novela que proyecta la noción de la historia oculta dentro del relato de Ricardo Piglia (2000). Las circunstancias vividas por Sánchez Mazas empujan a Cercas a indagar en torno al tema. La intención es distanciarse y desvincularse de la ficción: «un relato cosido a la realidad, amasado con hechos y personajes reales, un relato que estaría centrado en el fusilamiento de Sánchez Mazas y en las circunstancias que lo precedieron y lo siguieron» (Cercas, 2017: 237); pretende abordar una «elaboración discursiva, como si el concepto hiciera referencia a un tono, a una manera de narrar y a una batería de procedimientos de composición» (Peris Blanes, 2012: 140). A lo largo de seis años, el narrador y protagonista Cercas se concentra en rastrear distintas pistas para dar con las claves y las personas que rodearon el vagabundeo de Sánchez Mazas, escapando del Ejército Popular de la República y preservando su vida en un medio físico y humano que le era hostil, gracias a la ayuda de vecinos de la zona, fundamentalmente María Ferré, y de los «amigos del bosque», tres hombres huidos del ejército republicano a la espera de que concluya la guerra; posteriormente el foco de la trama se centrará en la búsqueda del soldado que perdona la vida a Sánchez Mazas en su huida. Tras una conversación con Roberto Bolaño, personaje de la novela, el protagonista se propone responder a la pregunta más importante de la novela, que se cifra en la necesidad de encontrar a ese personaje, conocer su historia y entender las motivaciones que le llevaron a comportarse como lo hizo. La disposición de Bolaño resulta clave para desatascar la pesquisa del protagonista, pero además es una declaración de intenciones del propio Cercas, dado que el autor chileno confiesa que conoció a un jovencísimo Cercas en Girona a finales de los setenta (Bolaño, 2004), se reencontrarían años después y compartirían una amistad. La capacidad irónica de Bolaño resulta gigantesca cuando escribe una reseña sobre Soldados de Salamina, en la que es un personaje secundario destacado, reconociendo el valor de la misma y señalando la importancia de Cercas como renovador de las letras españolas, dado que:

Su novela juega con el hibridaje, con el «relato real» (que el mismo Cercas ha inventado), con la novela histórica, con la narrativa hiperobjetiva, sin importarle traicionar cada vez que le conviene estos mismos presupuestos genéricos para deslizarse sin ningún rubor hacia la poesía, hacia la épica, hacia donde sea, pero siempre hacia delante (Bolaño, 2004: 178). 
El final de esta singular reseña bolañiana es todo un guiño del creador chileno, dado que termina del mismo modo que la novela de Cercas (2017: 400). En un aspecto de distribución del relato, Cercas estructura la narración de su libro en tres partes diferenciadas y la primera de ellas se sumerge en el relato a partir del suceso anecdótico protagonizado por Sánchez Mazas, político ultraderechista y escritor. La segunda parte ofrece una semblanza biográfica e histórica de Sánchez Mazas, un personaje histórico lleno de sombras y marcado por una experiencia extraordinaria. Por último, Cercas emprende una suerte de pesquisa en la que se propone esclarecer algunas cuestiones que no ha podido desentrañar con anterioridad, toma distancia y, como Piglia, devela el relato invisible y oculto, pero lo desnuda y en muchos aspectos lo hace explícito al lector. Además, como apunta Lugi Contadini (2011: 213), en el proceso metanarrativo de la novela, el escritor extremeño afincado en Cataluña ofrece abundantes referencias de historiadores y ensayistas literarios, ahondando en conspicuos detalles autorreferenciales; todo ello se articula, solapadamente, en una de las características más señeras de la obra.

\section{DAVID TRUEBA: PROYECTAR LA HISTORIA Y LA MEMORIA}

David Trueba tomó el testigo del relato para recorrer esos espacios omitidos y sepultados por el pactismo de finales de los setenta. Un pactismo que en su afán conciliador albergaba la esperanza de hacer una tabula rasa que, en gran parte, condenó al olvido el necesario reconocimiento de una colectividad anónima que luchó y sufrió frente al fascismo, y cuya aspiración no era la revancha, pero sí corresponder al esfuerzo y al sacrificio que millones de personas defendieron frente a la barbarie y el totalitarismo.

La necesidad de adecuar el tiempo narrativo impone que los seis años en los que se prolonga el relato literario se condensen temporalmente en el texto audiovisual y sin explicitarlo; el espectador asume que el tiempo transcurrido en la película se puede estimar en un período de uno o dos años. Los cambios operacionales que ejecuta Trueba a partir del texto matricial se sustancian en el hecho que supone el cambio de sexo del narrador y protagonista del relato, y de esta manera Javier Cercas pasa a ser Lola Cercas, que es interpretada por Ariadna Gil. Esta transformación no es anecdótica, pues explica de forma palmaria la autonomía que emprende Trueba al elaborar el guion y llevarlo a escena; además, forma parte del diálogo entre Javier Cercas y el propio cineasta:

El cambio de sexo del protagonista es algo que surgió de una larga conversación con Cercas, explica David Trueba. El personaje central del libro está inmerso en una crisis vital, en una duda, acorralado casi biológicamente. Creo que toda esa batalla se expresa en la persona de una mujer mucho más gráficamente que en un hombre $[\ldots]$. Convertir un 
personaje masculino en femenino otorga a la trama, en casos concretos, más tensión, más interés, nuevos perfiles (Harguindey, 2002: 34).

Las tribulaciones existenciales o incluso vitales que atraviesa el protagonista masculino de la novela y la protagonista femenina de la película pueden tener ciertas similitudes, pero son muy dispares, puesto que la película, además de reflexionar sobre muchas de las premisas que emanan de la novela, favorece una lectura de género. Lola lucha contra las propias obligaciones que la sociedad impone a las mujeres, una exigencia que también viene dada en su caso, a pesar de tratarse de una profesora universitaria, algo que no impide que los peajes del patriarcado se diluyan, pues parece, al contrario, que se refuerzan. La diferencia etaria entre ambos personajes no es significativa, pero sí lo es el hecho de que las circunstancias que atraviesan son muy distintas, puesto que Cercas (el personaje literario) se define de forma irónica y distanciada como un periodista con aspiraciones a escritor que decide emprender una búsqueda incierta para intentar encontrar personajes ordinarios de la historia en contextos y situaciones extraordinarias. El periodista protagonista sufre una ruptura matrimonial, la inestabilidad y la insatisfacción laborales junto a cierta crisis de madurez aderezada con una relación un tanto singular con una mujer que, aparentemente, comparte muy pocas afinidades o gustos con él. En el caso de Lola se puede decir que vive una compleja situación. Por un lado, también ha atravesado una ruptura sentimental, y de una u otra manera vive la exigencia de cumplir con el estándar social de ser madre a su edad, caracterizando de alguna manera una posición vital que se vuelve aún más tortuosa por la relación que mantiene con su padre, un anciano jubilado que vive en una residencia. La presentación de estos conflictos subraya una mirada femenina, pues como señala Sally Faulkner, del mismo modo que sucedía en El espíritu de la colmena (Víctor Erice, 1973), la película de Trueba emplea el punto de vista femenino, aunque el contraste se suscita porque en «el film de 1973 es el de una niña, y en la película de 2003 esta niña está hecha una mujer, sin embargo, tanto Ana como Lola tiene [sic] un padre que no es capaz de hablar de sus experiencias bélicas» (Faulkner, 2008: 166). Una situación que va a causar mayores desasosiegos tras la muerte de su progenitor en los primeros compases del film, alimentando aún más la crisis existencial y las circunstancias personales adversas que atraviesa Lola. La protagonista se afana en trabajar con sus colaboraciones en prensa y con sus clases de literatura en la Universidad de Girona, trabajo que ha comenzado recientemente; ambas actividades parecen ser el salvavidas de un devenir marcado, en cierto sentido, por la frustración y las insatisfacciones que soporta.

Este escenario de crisis, creativas y vitales, podría resultar análogo en ambos protagonistas, pero el personaje de Lola proyecta otro tipo de inquietudes $\mathrm{y}$, sobre todo, de reflexiones a la hora de enfrentarse a la 


\section{David García-Reyes}

investigación que comienza buscando los detalles y las certezas de lo sucedido a Sánchez Mazas en el Santuario de Santa María del Collell. El contexto geográfico sigue siendo la ciudad de Girona, donde reside Javier Cercas, y que es el lugar en el que se desarrolla gran parte de la trama, aunque otra circunstancia que cambia completamente el relato consiste en que David Trueba prescinde de la figura de Roberto Bolaño como personaje en la película. La opción de que el escritor chileno interpretase a su personaje, tal y como aparece en el texto matricial, era factible para funcionar de la misma manera que los amigos del bosque, ejerciendo igual que en el libro como los testigos históricos que desgranan las vicisitudes y penalidades sufridas por Sánchez Mazas en el tiempo presente, pero estos y Chicho Sánchez Ferlosio, hijo de Sanchez Mazas, son los únicos personajes reales con los que quiere contar el director y guionista. No obstante, aunque en ese momento la figura de Bolaño tenía cierto reconocimiento en el ámbito de las letras hispánicas, no ostentaba la proyección editorial y el impacto mediático global que tendría pocos años después de su fallecimiento. Por cuestiones funcionales y narrativas puede entenderse que la elección de Trueba fuese sustituir al personaje del escritor por el de Gastón Elquiza, un alumno universitario de origen mexicano interpretado por Diego Luna, que funciona también como catalizador del relato e inductor de pistas en las pesquisas de la protagonista, así como un punto de tensión física para la profesora, aunque esta seducción no llegue a concretarse. Gastón, nieto de un niño de la guerra refugiado en México, tiene muy presente la memoria de su abuelo, del mismo modo que Bolaño evoca el final del presidente chileno Salvador Allende cuando es atacado en el Palacio de la Moneda durante el Golpe de Estado de 1973. Allende es la referencialidad de la noción de héroe de la historia, que obvia la película pero que cita la novela:

Alguien que se cree un héroe y acierta. O alguien que tiene el coraje y el instinto de la virtud, y por eso no se equivoca nunca, o por lo menos no se equivoca en el único momento en que importa no equivocarse, y por lo tanto no puede no ser un héroe. O quien entiende, como Allende, que el héroe no es el que mata, sino el que no mata o se deja matar (Cercas, 2017: 338-339).

La noción heroica en lo expresado por el personaje de Bolaño es ese «heroísmo concreto o anecdótico [...] que se representa en un acto aislado, en un instante en el que el héroe debe tomar una decisión que puede cambiarlo todo» (Ródenas de Moya, 2017: 153-154).

En torno a las relaciones personales que establece Lola, destaca una turbulenta amistad que entabla con el personaje de Conchi (Maria Botto), que contaba con una presencia notable en la novela y que funcionaba como contrapunto cómico, algo que se aprecia lateralmente en el film y que se verá potenciado en la novela gráfica. En la película, la pitonisa trabaja en una televisión local y brinda sus servicios de cartomancia en la residencia 
del padre de Lola, que es donde se conocen las dos mujeres. Trueba decide mantener la atracción hacia el personaje protagonista, pero hay un cambio de orientación sexual, dado que a Conchi le gusta Lola, que no comparte los intereses de la adivina. Trueba sitúa a Gastón y a Conchi como personajes claves para que Lola prosiga su búsqueda, y las relaciones que comparte con ellos también se ven comprometidas por malentendidos y ambigüedades sentimentales y amicales.

Además, el director altera el orden de la novela y sustituye la aparición de Rafael Sánchez Ferlosio en el texto literario por la de su hermano Chicho, junto con la aparición de Miquel Aguirre, que funciona como el elemento de nexo con los testimonios de los que conocieron a Sánchez Mazas, que los llamó «los amigos del bosque», y las vicisitudes de estos tras huir de las tropas republicanas. La mezcla de noticiarios documentales y el uso de CGI (Computer-generated imagery) para insertar al actor Ramon Fontserè como Sánchez Mazas otorgan a la película una pátina de cine verista en su afán de reforzar el relato y una estética próxima al documental para proyectarse como una obra de no ficción análoga al texto literario. La voluntad de Trueba de trabajar con un equipo reducido y la labor de Javier Aguirresarobe como responsable de la fotografía, o los solos de viola minimalistas de Amalia Rodríguez constituyeron algunas de las mayores virtudes de la película en su aspiración por hacer un cine de guerrilla, además de rodar a tal efecto en Super $16 \mathrm{~mm}^{2}$, todo para ofrecer una narración adherida al recuerdo y a la memoria. El propio director madrileño reconocía, en conversación con Cercas, la importancia del cine de Basilio Martín Patino a la hora de ejecutar su propuesta audiovisual (Cercas y Trueba, 2003: 26). Los tonos fríos predominan en el conjunto, pero el tiempo histórico y los avatares de Sánchez Mazas subrayan unos colores plomizos y quemados frente al tiempo presente del relato, que contiene tonalidades cálidas dentro de una paleta cromática en la que destacan los colores fríos en el conjunto. Así, tanto la construcción del film como la de la novela se ordenan en torno a la búsqueda de respuestas, pero también emerge la historia invisible o soterrada que diría Ricardo Piglia, explícita tanto en la novela como en la película, pues el sentido final de la investigación no es otro que dar con el paradero de Miralles, interpretado por Joan Dalmau, como el supuesto y anónimo soldado del V Cuerpo del Ejército del Ebro liderado por el comandante Enrique Líster, y los motivos de por qué dejó escapar con vida a Sánchez Mazas. Ese acto de misericordia expresa la insensatez de la guerra, dignificando el papel de millones de personas obligadas a marchar a un exilio tan incierto como atroz, pues en muchos casos les aguardaba el confinamiento en campos de concentración franceses o la diáspora hacia América, cuando no la reclusión y la muerte de muchos de ellos en

\footnotetext{
${ }^{2}$ Posteriormente para la distribución comercial de la cinta, el formato Super $16 \mathrm{~mm}$ fue ampliado a $35 \mathrm{~mm}$ para ser proyectado en salas.
} 


\section{David García-Reyes}

campos de exterminio nazis al poco de comenzar la II Guerra Mundial. El propio periplo biográfico de Miralles así lo subraya: en su racconto, el veterano exiliado explica la década que estuvo luchando y penando en los frentes de España, de África y de Europa, con la esperanza de acabar con el fascismo y quizás regresar a su país, pero en el camino consumirá su juventud y perderá a su familia y a sus amigos, esos jóvenes que dejaron la vida sin haber disfrutado de los placeres que esta podía haberles ofrecido.

Por todo lo anterior, lo más orgánico y llamativo de la propuesta de Trueba es su capacidad para incorporar el recuerdo de los verdaderos amigos del bosque y así entender el valor testimonial de su relato, que si bien ya aparecía en el texto de Cercas, cuenta en la película con segmentos de naturaleza documental integrados con precisión en el montaje, recursos diegéticos del audiovisual que permiten dinamizar el relato fílmico y las distintas tramas y subtramas sin cesuras, desde la encrucijada vital de Lola, la investigación sobre la huida de Sánchez Mazas, junto con los vívidos recuerdos de las personas que ayudaron al político falangista y el colofón que supone encontrar a Miralles, ese antihéroe que parece encarnar la amargura de la derrota, la melancolía de las personas que dejó en el camino y el distanciamiento con un suceso que juzga indiferente a nivel existencial pero que resulta de capital importancia para la investigación emprendida por Lola y sus implicaciones. De esta manera, el film permite poner cara a los ancianos amigos del bosque, que van desfilando y narrando a Lola sus testimonios sobre Sánchez Mazas. Así, aunque uno de ellos, Pere Figueras, ha muerto hace quince años, pueden relatar las peripecias del líder de Falange en la comarca de Banyoles, su hijo Jaume Figueras, y su hermano Joaquím, superviviente junto a Daniel Angelats. Los amigos del bosque se expresan en lengua catalana, todas las personas reales de Cornellà del Terri hablan en catalán, algo que no pasa ni en la novela ni en la novela gráfica, detalle que ofrece matices enormemente significativos para apuntar una lectura distinta a la de la novela. Trueba visibiliza el uso de una lengua oficial y sutilmente señala que los personajes se comunican en una lengua denostada y perseguida por el franquismo y, en el contexto de producción del mismo, por sectores conservadores españoles, sirviéndole también para emular, enfatizar y reforzar el tono documental y de «no ficción» que ya sugería la novela de Cercas.

El relato audiovisual realiza un ejercicio sintético cuando vemos los recorridos de Sánchez Mazas cuando huye de Madrid, tras estar refugiado en la embajada chilena, su atropellada odisea buscando cruzar las líneas estando en territorio enemigo, su apresamiento y su trasladado desde el barco prisión Uruguay al Santuario de Santa María del Collell. El relato se intercala con la génesis de lo escrito por Lola y la situación de enero de 1939 con miles de refugiados marchando a Francia y los presos franquistas como Sánchez Mazas conducidos en un vehículo por parte de los hombres de Líster. Los convoyes de refugiados son bombardeados en su repliegue, pero en ningún caso la capacidad económica de la producción 
cinematográfica aspira a poder mostrar de forma más amplia la multitudinaria y abrupta retirada. Lola luego va al Collell a conocer in situ la geografía de la trama. Se evoca un flashback del fusilamiento intercalado por las sensaciones de Lola proyectando las escenas del relato. Y veremos a Sánchez Mazas huyendo por el bosque, interceptado por el soldado, que le encañona y luego le deja marchar. La sugestión del lugar donde se produjo el fusilamiento en masa de prisioneros del bando rebelde hace que Lola se sumerja en el proceso de elaboración del libro. Los amigos del bosque ya han transmitido a la escritora que a Sánchez Mazas lo habían visto durante la reclusión previa al fusilamiento, en la que los presos y los milicianos escuchan al joven cantar la canción «Suspiros de España» (con música de Antonio Álvarez Alonso y letra de José Antonio Álvarez Cantos). La significación y la potencial carga dramática de este pasodoble es un elemento clave en la posterior búsqueda del héroe desconocido y cumple un papel que aglutina el sentir de las dos Españas que describió Antonio Machado. Al leer un primer tratamiento del libro, Conchi considera que le falta algo, opinión compartida con Lola, que no acaba de dar con el cierre del libro. La carencia del mismo es conocer el valor del héroe y saber de ese ser desprendido, un héroe que no busca protagonismo. El giro que cambia el desarrollo de la investigación viene precedido por una noticia que Lola y Conchi ven en la televisión: un hombre que salva a varias personas en un incendio en Madrid y perece en el mismo sacando a los vecinos del inmueble, anécdota que en la novela es narrada por el personaje de Bolaño (Cercas, 2017: 339-340). La introducción de la idea del héroe ya ha sobrevolado la pesquisa con anterioridad, pero al graficarse induce a que Lola pida a sus alumnos un ensayo sobre un héroe. Y de esta manera, Gastón redacta un texto en el que describe sus experiencias en el camping Estrella de Mar de Castedelfells, apropiándose de nuevo de las experiencias y opiniones de Bolaño en el libro. Para hablar de alguien semejante a un héroe, Gastón describe a Miralles, un veterano de la guerra civil, recluta posteriormente en la columna formada por el General Jacques-Philippe Leclerc durante la II Guerra Mundial. El estudiante mexicano utiliza una grabación en Super 8 que conserva de su etapa como empleado del camping para profundizar en el conocimiento que tiene del viejo soldado. La necesidad de encontrar al héroe, no sin algunas dificultades, conduce a Lola hasta Miralles, el posible soldado que perdonó la vida a Sánchez Mazas. En su búsqueda, lo encontrará viviendo su vejez en una residencia de ancianos de Dijon. Al entrevistar al anciano, los fragmentos de su historia refuerzan su idea de que se trata del soldado que salvó a Sánchez Mazas, y al despedirse Miralles apunta que «Andas buscando a un héroe y los héroes no sobreviven». Al despedirse, como en el texto de Cercas, el misterio y la incógnita se perpetúan o no, pues quizás lo que simboliza Miralles valida el acto del soldado que perdonó la vida a Sánchez Mazas. Miralles, en la novela y en sus dos reescrituras, muestra una ambigüedad final que resulta «oscilante entre la invención 


\section{David García-Reyes}

indispensable por parte del narrador y la culminación real de sus pesquisas para localizar al anciano [que] planea sobre todo en el desenlace y no se resuelve» (Ródenas de Moya, 2017: 141).

Igual que en la novela, Miralles le pide un abrazo a Lola, que accede y poco después se monta en el taxi. Antes de partir, baja la ventanilla y le cuenta el baile del soldado con el fusil cantando el pasodoble de «Suspiros de España», pero el anciano vuelve a negar ser el miliciano, de forma que la ambigüedad flota en el aire mientras Lola rumia que volverá a verle despidiéndose en el asiento del taxi. La escena muda del soldado bailando bajo la lluvia cierra la película. A modo de corolario y reforzando la enorme presencia femenina del personaje interpretado por Ariadna Gil, Faulkner considera que la película tiene como eje e hilo conductor de la trama a Lola y es precisamente la importancia del pasado, del valor de la memoria y de su capacidad para interpretarlo lo que le sirve a la protagonista para conocer y comprender el presente; los espectadores, a pesar de ignorar muchas de la motivaciones que le llevan a realizar su pesquisa, se «involucran en el mundo investigativo de Lola porque cada recreación histórica en Soldados de Salamina corresponde a la mirada interior de la protagonista» (Faulkner, 2008: 167-168), y el propio Cercas, asistiendo al rodaje, explicaba con acierto los motivos que habían llevado a ese punto de vista y develaba el sentido último de la película de Trueba, al que

le interesa el punto de vista femenino sobre la guerra civil, mucho más infrecuente que el masculino. Le interesa hacer visible un tema que, aunque absolutamente fundamental, en la novela está sólo insinuado: el de la continuidad entre padres e hijos (la urgencia por tener uno suele ser, en una mujer de treinta y tantos años como la protagonista de David, mucho más apremiante que en el hombre de la misma edad que protagoniza mi novela, por razones puramente biológicas) (Harguindey, 2002: 34).

\section{José Pablo García: MirAdas SECUENCIALES A LA "NO FiCCIÓN"}

José Pablo García ya se había especializado en tratar episodios ambientados en la historia de España y vinculados con la cultura popular, destacando la novela gráfica Las aventuras de Joselito: el pequeño ruiseñor (2015), biografía de la estrella infantil de la canción y el cine español durante el franquismo, y los encargos por parte de la Editorial Debate de llevar al ámbito de la novela gráfica dos ensayos originales del hispanista británico Paul Preston. En primer lugar, García asume la responsabilidad en un trabajo titánico de síntesis y adaptación, ejecutando la traslación secuencial de La Guerra civil española (2016). A partir del monumental ensayo de Preston publicado originalmente en 1988, el autor malagueño se ocupa de armar una narración gráfica documental en la que sobresale su uso de una paleta cromática sostenida en bitonos de gamas de rojos y negro, y acude al empleo de un dibujo realista que se aleja de la caricatura. 
Un año después, Debate le vuelve a encargar que se ocupe de adaptar un ensayo breve de Preston publicado originalmente en 2012: de título homónimo, La muerte de Guernica (2017) de García, se ocupa de forma documental de relatar gráficamente el bombardeo y la matanza; en este caso el autor de cómic opta por una solución formal en la que se aplica la misma estética de su precedente, pero elige una gama de colores fríos, recursos bitonos de azules y negro con una carga estética que hace reconocible la proyección fotográfica y pictórica de la masacre, remitiendo al Guernica (1937) de Pablo Ruiz Picasso, probablemente el lienzo más célebre del siglo XX. Utilizando las gamas frías empleadas por el pintor, García intenta transmitir la carga cromática de las fotografías periodísticas por las que fue conocida internacionalmente esta acción de guerra, encaminada a castigar a la población civil, pues la localidad vizcaína no era, desde luego, un objetivo militar que justificase semejante despliegue bélico. En estos trabajos, García también se apoya en el abundante material fotográfico de los sucesos históricos, técnicas que va a replicar en posteriores obras y que han marcado una senda por la que han transitado otros autores; siguiendo esta estela y por encargo del mismo grupo editorial de Debate, Penguin Random House, destaca el trabajo de Quique Palomo, responsable de las adaptaciones gráficas Vida y muerte de Federico García Lorca (2018) y Ligero de equipaje: vida de Antonio Machado (2019), narraciones que adaptan las biografías de ambos escritores realizadas por Ian Gibson y publicadas originalmente en 1988 y en 2006.

Esta prolífica tendencia no excluye otras adaptaciones impulsadas por Penguin Random House, y que se relacionan con la obra de Javier Cercas. Antes de llegar a la novela del escritor de Ibahernando, merece la pena detenerse en una adaptación que tiene como texto matricial una obra literaria de «no ficción» de Roberto Bolaño: se trata de la novela gráfica Estrella distante (2018), con arte de Fanny Marín y guion de Javier Fernández. Estrella distante fue publicada originalmente por Bolaño en 1996 y cuenta con una propuesta que la hermana con Soldados de Salamina (2001) de Cercas. El interés de Ramdom House en trasladar la obra de Cercas a novela gráfica tuvo como intermediario y promotor a Claudio López Lamadrid, editor responsable de la división en español del holding editorial. El escritor dejó hacer sin seguir el proceso (Andreu, 2019) y un tanto ajeno a todo lo relacionado con el noveno arte. Para García su incursión en la traslación secuencial de la novela de Javier Cercas era, en muchos aspectos, un proyecto que se adaptaba a las destrezas que el historietista malagueño había demostrado con anterioridad. De nuevo llevar a la narración figurativa la novela volvía a ser un encargo por parte de Random House para uno de sus sellos editoriales.

Soldados de Salamina (2019) de José Pablo García es, formalmente, una novela gráfica que recurre a un estilo que alterna el realismo figurativo y el uso incidental de la bicromía, pero a diferencia de las adaptaciones de los ensayos de Preston, el uso y la aplicación en sus viñetas del color conforma 


\section{David García-Reyes}

dos terceras partes de la narración. García inicia la narración con una apertura (2019: 5-9), casi a modo de prefacio, en la que presenta al protagonista y narrador y al germen de la búsqueda que dispara la acción narrativa. El guionista e ilustrador respeta los tres bloques capitulares de la narración literaria, es decir: «1. Los amigos del bosque», «2. Soldados de Salamina» y «3. Cita en Stockton». Se pueden señalar cambios operativos necesarios en la ordenación del relato secuencial, pero conservando siempre la analogía y linealidad que comparte con la novela. El empleo de bitonos en azules y negro suele darse en los pasajes documentales más apegados a los sucesos de la historia o la memoria. También recurre a la reproducción fotográfica en algunas partes muy concretas, como en la reproducción de los libros más destacados de Sánchez Mazas (García, 2019: 12 y 93). El uso además de los bitonos azules coincide con la reproducción gráfica del artículo «Un secreto esencial» (García, 2019: 1315), y sobre todo en el capítulo «2. Soldados de Salamina» (2019: 45-97), segmento central de la novela gráfica que se ocupa de la semblanza biográfica del escritor y líder falangista; aunque hay viñetas en bitonos rojos, prevalecen las gamas frías de los añiles y los fondos de página, y los márgenes están teñidos en sepia, a diferencia del grueso de la novela gráfica, donde van en blanco. Esta es claramente una decisión ideológica y de dirección autoral por parte de García, que remarca el tiempo y el contexto narrativos, así como la de desarrollar la ambientación de una historia que recorre geografías tan distintas como locaciones de Cataluña, Francia o África.

La parte del trabajo de García más arriesgada - del mismo modo que la elección del casting en el caso de Trueba- llega con el diseño de los personajes: Cercas, el protagonista, es un periodista con aspiraciones a escritor que ha perdido a su padre y se ha separado de su mujer, y es un autor en busca de una historia, un ser humano que sufre una crisis existencial y de madurez. El personaje que concentra las mayores dosis y flujos de humor es la singular Conchi, pitonisa y amante de la vida campestre; el diseño del personaje es un cruce entre lo popular, lo lumpenesco y lo chabacano. En cualquier caso, es un personaje rebosante de ironía y sabiduría popular, medular en la dirección de la historia. Conchi, con su arrojo y enérgica personalidad, complementa la inestabilidad del inseguro y timorato protagonista, ya que, cuando este atraviesa dudas y tribulaciones, la pitonisa siempre está ahí. La presentación del personaje en los primeros compases de la novela gráfica es una fantástica síntesis del mayor logro entre las caracterizaciones de la narración de José Pablo García (2019: 26-29), con guiños muy pop y un estilismo, con el pelo rubio cardado y maquillaje facial en generosas cantidades, más propio de las Olimpiadas de Barcelona'92 que de mediados o finales de la última década del siglo XX.

La aparición de Roberto Bolaño como personaje en el último tercio del relato (García, 2019: 102), sustituido por Gastón en la película, cobra 
una importancia superlativa en la novela gráfica: no solamente es vertebral para orientar la dirección última del relato al introducir a Miralles como el potencial soldado que pudo perdonar la vida a Sánchez Mazas, sino que cobra un empaque totémico por la importancia que el autor chileno ha tenido desde su muerte (2003) y la proyección de su figura y del conjunto de su obra. Pero al margen de lo anterior, García diseña a un Bolaño digno del escritor y del personaje de la novela, siendo un caudal de anécdotas, de giros de humor, y revive en viñetas, aunque pueda ser una imagen idealizada, al enorme autor de Los detectives salvajes y 2666.

Y llegados a Miralles, el dibujante malagueño esboza su propia reescritura dibujada del personaje, muy alejada del actor Joan Dalmau. Es el diseño de un hombre que supera los setenta años, alopécico, con un bigote blanco ${ }^{3}$, con sobrepeso y una enorme cicatriz que le recorre desde el lado izquierdo del rostro hasta todo el costado izquierdo de su cuerpo (García, 2019: 108), producida por las heridas tras pisar una mina en Austria (2019: 112). Bolaño lo conocerá en los cuatro veranos que pasa como trabajador en el camping Estrella de Mar; este período se muestra en un largo flashback secuencial en bitonos rojos (2019: 107-115) y se completa con otra de las citas que hace de la novela de Cercas, puesto que el título del último tramo de la novela y del cómic hace referencia a Stockton, una decadente ciudad en el interior del estado de California en la que se ambienta la película Fat City, ciudad dorada (Fat City, 1972) de John Huston, que a su vez se basa en la novela homónima (1969) del escritor Leonard Gardner, también guionista de la cinta. La película relata la historia de Tully (Stacy Keach) y Ernie (Jeff Bridges), dos boxeadores que aspiran a cambiar su escasa suerte en un contexto tan pesimista y atroz como propicio al fracaso. Después de la proyección, Miralles y Bolaño toman una copa y departen hasta la madrugada, el veterano se despide del melancólico trabajador del camping con el grito «Nos vemos en Stockton» (García, 2019: 126), que servirá a Cercas para vencer las reticencias del jubilado de aceptar la visita del periodista en la residencia de ancianos donde vive en la ciudad francesa de Dijon.

Rafael Sánchez Mazas, los amigos del bosque, Rafael Sánchez Ferlosio, Francisco Franco, José Antonio Primo de Rivera, Antonio Machado o Jaime Gil de Biedma son representados con una intencionalidad verista que contrasta con la representación que José Pablo García hace de María Ferré, y no es que sea poco realista, pues es una anciana muy corriente (García, 2019: 41). En este punto es evidente que el visionado de la película de

\footnotetext{
${ }^{3}$ Con anterioridad, José Pablo García había dibujado al personaje del soldado con la misma nariz y un bigote más fino, una identificación que ilustra desde la portada de la edición cartoné de la novela gráfica y que presenta una fisonomía y unos rasgos muy alejados de los del miliciano interpretado por Alberto Ferreiro en la película de Trueba, y dicha imagen del miliciano recorre visualmente todo el relato gráfico (García, 2019: 8, 15, 66-67, 79-81 y 141), instalando en el imaginario del lector una asimilación que lleva indefectiblemente a Miralles.
} 


\section{David García-Reyes}

Trueba ayuda a describir gráficamente algunos espacios, y para un espectador atento el diálogo entre el film y la novela gráfica tiene conexiones que abarcan la elección de los extractos documentales, el encuadre o la composición de algunas viñetas o escenografías, que van desde Banyoles (2019: 39-40) a la traza urbana de la ciudad de Girona (2019: 22). Es uno de los fragmentos más evidentes, en el diálogo con la película, la conversación que el periodista Cercas mantiene en la novela gráfica con Daniel Angelats (2019: 41-42), estableciendo un paralelismo en la composición y en los lugares con la escena en la que Lola Cercas conoce el testimonio del susodicho miembro de los amigos del bosque. Por lo anterior, en las escenas eliminadas del metraje final disponibles en la copia comercial del film se pueden verificar no solo descartes que hubieran densificado la trama y la experiencia de Sánchez Mazas: parte de lo eliminado en la edición final del film por parte de Trueba es la reconstrucción en el Santuario del Colell y la entrevista a la María Ferré real, la mujer que ayudó, junto a sus padres, a Sánchez Mazas a sobrevivir junto con los amigos del bosque. La mencionada caracterización del personaje determina que García descartó la imagen documental de Ferré, bien por no haber accedido a los extras de la película o por otros motivos. De ahí que las características de la persona real no fueran tenidas en cuenta, pues en la novela gráfica aparece representada como una anciana muy distinta a la que vemos en las escenas que quedaron fuera de la película.

Las premisas argumentales, estilísticas y estéticas que tanto en la novela como en la película habían configurado el imaginario en torno a Soldados de Salamina, suponían un obstáculo añadido para realizar una novela gráfica solvente. Las deudas con sus predecesoras no se niegan; al contrario, se reconocen e identifican. En lo que, tal vez, el lector de la novela gráfica queda huérfano es en otra dirección. José Pablo García no se apropia gratuitamente de aquellas claves narrativas o temáticas, ofrece una nueva formulación semántica y sígnica, a partir del lenguaje del cómic. El autor indaga en las posibilidades formales del relato en su ámbito secuencial, y la respuesta de por qué no se aventura en una propuesta aún más arriesgada puede deberse a la naturaleza y obligaciones del encargo, dado que García ya había mostrado su capacidad para compaginar estilos figurativos distintos y una plétora de recursos de enorme versatilidad, como confirma su biografía gráfica de Joselito. Al no afrontar otras prospecciones formales y narrativas, configura la novela gráfica como una equivalencia modular que ofrece una lectura asequible para cualquiera que se acerque a la narración. No obstante, el mandato laboral que hubiera podido deslizar la editorial no contraviene de ningún modo la capacidad autónoma del autor de historietas, que como se puede apreciar decide todo lo relacionado con la creación de los personajes y el desarrollo de la obra; se intuye más una autocontención derivada de la significación que se deja sentir a partir de todo lo relacionado con la novela y, por extensión, 
también con el film. García adopta una posición que busca armonizar con el cómic las complejidades narrativas e ideológicas que pueden suscitar el texto fuente y su trasvase fílmico. Todo lo anterior desde una posición genuina por parte del creador malagueño, porque especular con el potencial de haber realizado un planteamiento menos escrupuloso con sus antecedentes es solo eso, una elucubración respecto del enorme atractivo que hubiera supuesto diferenciarse de las convenciones que la novela gráfica presenta. Por tanto, en la reescritura de la narración figurativa se hubiera podido ofrecer un cuestionamiento del repertorio precedente para reflexionar sobre la naturaleza discursiva y crítica respecto a las referencialidades literaria y cinematográfica de las que bebe la novela gráfica de García.

\section{PARA UNA DiscuSIÓN}

Al entender cada manifestación cultural o, si se quiere, cada forma de contar una historia, desde la novela matricial de Cercas, encontramos un espacio de enorme versatilidad para ser susceptible de ser retomado en formato audiovisual y como novela gráfica.

Jaume Peris Blanes (2012) considera que la película de Trueba disuelve su compromiso político al tomar un camino discursivo en el que el estilo documental espectaculariza el contenido y muestra un relato que puede ser leído como un alegato superficial que defiende de forma reductiva el debate y la reflexión sobre la memoria histórica. Aunque fuera así, el valor político de la propuesta en el contexto en el que se estrena y se rueda es significativo porque confronta con un discurso oficial que menosprecia el pasado con un gobierno más preocupado por las turbulencias de la política exterior de Oriente Medio y por el crecimiento de la economía inmobiliaria que por dimensionar conflictos históricos no resueltos que separan al conjunto de la sociedad. Independientemente de que ciertos recursos o el conjunto del resultado expongan un carácter trivial o demasiado plano, la voluntad de Trueba en su película es coherente, confirmada por la inquietud de armar un film que evita lo panfletario. Del mismo modo que el libro de Cercas modulaba una postura autorreflexiva y crítica frente a lo narrado, el largometraje no pretende ser autocomplaciente, no recurre al maniqueísmo de producciones grandilocuentes o a las convenciones que injustamente le suelen achacar al cine español sobre la guerra civil.

La novela gráfica tiene otras pretensiones, más didácticas, y la suya es quizás la más aséptica ideológicamente hablando, pero es fruto del tiempo transcurrido desde la publicación de la novela y el estreno de la película. Por ello, la aparición de la novela gráfica se ha beneficiado del reconocimiento de la obra literaria y de las aportaciones del film. El uso del humor en el cómic, ausente en la película, estaba subrayado por la ironía del texto fuente; esa voluntad de flujo irónico es compartida por Cercas y García, y desarrollada tanto en la prosa como en la narración 


\section{David García-Reyes}

figurativa, permitiendo adivinar uno de los mayores atributos que definen el estilo o los estilos del historietista malagueño, que confía en su capacidad para epatar gráficamente sin caer en la caricatura. Aunque pueda echarse de menos cierto rupturismo en lo estético y en lo narrativo, José Pablo García ha conservado su espacio autoral y ha expandido la recepción y la difusión de la novela y de la película.

El conjunto de estas obras no busca confrontar, sino reconocer esa memoria y poner en valor el recuerdo y las experiencias personales de mujeres y hombres comunes que vivieron y soportaron momentos extraordinarios. Soldados de Salamina, en todas sus formas, alienta y estimula la capacidad crítica de lectores y espectadores. La excusa es un recuerdo imprescindible de una biografía, la de Sánchez Mazas, que se antoja finalmente indiferente; ese recuerdo «configura nuestros vínculos con el pasado; las maneras en las que recordamos nos definen en el presente. Como individuos y como sociedades, necesitamos del pasado para construir y anclar nuestras identidades y para alimentar una visión del futuro» (Huyssen, 2001: 143), esa mirada que es una prospección que se dirige hacia delante, como acaba de rematar la aliteración final de la novela que homenajeó Bolaño en su reseña, esa mirada de Lola tras la ventana del taxi al despedirse de Miralles o el periodista Cercas, protagonista de novela y cómic, observando el exterior del tren en el que viaja y barrunta un futuro, «caminando hacia delante bajo el sol negro del ventanal, sin saber muy bien hacia dónde va ni con quién va ni por qué va, sin importarle mucho siempre que sea hacia delante, hacia delante, hacia delante, siempre hacia delante» (Cercas, 2017: 400).

\section{BIBLIOGRAFÍA CITADA}

Altarriba, Antonio y Kim (2009), El arte de volar, Alicante, Edicions de Ponent.

ANDREu, Sergio (2019), «La adaptación de Soldados de Salamina lleva la memoria histórica al cómic», Agencia Efe [En línea: https://www.efe.com/efe/espana/cultura/la-adaptacion-desoldados-salamina-lleva-memoria-historica-al-comic/10005-3946393. Fecha de consulta: 09/03/2020].

Aróstegui, Julio (2004), «Retos de la memoria y trabajos de la historia», Pasado y memoria: Revista de historia contemporánea, 3, págs. 5-58.

Bolaño, Roberto (2004), Entre paréntesis, Barcelona, Anagrama.

CerCAS, Javier (2017), Soldados de Salamina, Madrid, Cátedra.

Cercas, Javier y David Trueba (2003), Diálogos de Salamina: un paseo por el cine y la literatura, Barcelona/Madrid, Tusquets/Plot.

CONTADini, Luigi (2011), «Soldados de Salamina: storia di una salvezza possibile», Confluenze: Revista di studi iberoamericani, 3/1, págs. 208226. 
García, José Pablo (2019), Soldados de Salamina, Barcelona, Reservoir Books.

GiL Montoya, Rigoberto (2013), «Sujetos de la historia: entre excéntricos y paranoicos», Sophia, 9, págs. 68-78.

Harguindey, Ángel S. (2002), «Muerte y resurrección de Sánchez Mazas», El País, pág. 34.

Huyssen, Andreas (2001), En busca del futuro perdido. Cultura y memoria en tiempos de globalización, Buenos Aires, Fondo de Cultura Económica.

ISER, Wolfgang (1987), El acto de leer: teoría del efecto estético, Madrid, Taurus.

LARRAZ, Fernado (2014), «La Guerra Civil en la última ficción narrativa española», Studia historica. Historia contemporánea, 32, págs. 345-356.

LIIKANEN, Elina (2013), «La herencia de una guerra perdida: La memoria multidireccional en Los rojos de ultramar de Jordi Soler», Olivar, 20, págs. 77-109.

Peris Blanes, Jaume (2012), «Los agujeros del relato real. Usos del archivo y del testimonio en Soldados de Salamina (Cercas/ Trueba)», Archivos de la filmoteca, 70, págs. 139-150.

Ródenas DE MOYA, Domingo (2017), «Introducción», en J. Cercas, Soldados de Salamina, Madrid, Cátedra, págs. 9-188.

Scolari, Carlos A. (2019), Media Evolution. Sobre el origen de las especies mediáticas, Buenos Aires, La Marca Editora.

Piglia, Ricardo (2000), Formas breves, Barcelona, Anagrama.

STAM, Robert (2014), Teoría y práctica de la adaptación, México, UNAM.

Fecha de recepción: 21/05/2020.

Fecha de aceptación: 25/07/2020. 